\title{
Características estruturais e agronômicas da Brachiaria brizantha cv. Xaraés submetida a doses de nitrogênio ${ }^{1}$
}

\author{
Welton Batista Cabral ${ }^{2}$, Alexandre Lima de Souza ${ }^{2}$, Emerson Alexandrino ${ }^{3}$, Fábio Luiz \\ Buranelo Toral ${ }^{2}$, Josimar Nogueira dos Santos ${ }^{2}$, Marcus Vinícius Pavoni de Carvalho ${ }^{2}$
}

\footnotetext{
${ }^{1}$ Financiado pela Fundação de Amparo à Pesquisa do Estado de Mato Grosso - FAPEMAT.

2 Universidade Federal de Mato Grosso - UFMT.

3 Universidade Federal do Tocantins - UFTO.
}

RESUMO - Objetivou-se neste experimento avaliar as características estruturais e agronômicas da Brachiaria brizantha cv. Xaraés sob diferentes doses de nitrogênio (0; 125; 250; 375 e 500 kg.ha-1 de N) cultivadas no Campus Universitário de Rondonópolis, Mato Grosso, no período de 12/10/2006 a 23/8/2007. Os tratamentos foram dispostos em delineamento inteiramente casualizado com quatro repetições. Os resultados obtidos foram submetidos às análises estatísticas agrupando-se os dados em dois períodos, águas e ao longo do ano. As doses de $\mathrm{N}$ influenciaram o número de folhas aparecidas para a época chuvosa, assim como o número de folhas verdes. O número de folhas totais foi influenciado pelas doses de $\mathrm{N}$ nas águas e ao longo do ano. Houve incremento de $27 \%$ no comprimento médio da lâmina foliar para a dose de 343,9 kg.ha ${ }^{-1}$ de $\mathrm{N}$ para o período das águas. A densidade de perfilhos foi influenciada pelas doses de $\mathrm{N}$ para ambos os períodos de avaliação, sendo que a altura das plantas foi influenciada pelas doses de $\mathrm{N}$ para as duas épocas avaliadas. $\mathrm{O}$ aumento na disponibilidade de matéria seca por hectare foi de $87,5 \%$ para a maior dose de $\mathrm{N}$ nas águas (333,3 kg.ha-1 de $\mathrm{N}$ ) em comparação ao tratamento testemunha. A adubação nitrogenada influencia positivamente todas as características relacionadas ao crescimento e à produção de massa, principalmente no período chuvoso, quando a adubação deve ser parcelada em quatro ou cinco doses, não justificando adubações no período seco do ano.

Palavras-chave: adubação nitrogenada, morfogênese, pastagens, perfilhamento

\section{Structural characteristics and agronomic traits of Brachiaria brizantha cv. Xaraés subjected to nitrogen levels}

\begin{abstract}
The objective of this experiment was to evaluate the structural characteristics and agronomic traits of Brachiaria brizantha cv. Xaraés under different nitrogen levels (0, 125, 250, 375 and $500 \mathrm{~kg}^{-h^{-1}}$ of N) grown in Campus Rondonópolis, Mato Grosso, in the period 10/12/2006 to 08/23/2007. The treatments were arranged in a randomized design with four repetitions. The results were submitted to statistical analysis by grouping the data into two periods: rain and throughout the year. The $\mathrm{N}$ influenced the number of leaves appeared at the time rainy, and the number of green leaves. The number of leaves was influenced by $\mathrm{N}$ rates during the rain and throughout the year. There was an increase of $27 \%$ in the average length of the leaf blade to the dose of $343.9 \mathrm{~kg} \mathrm{ha}^{-1} \mathrm{~N}$ for the rainy season. The density of tillers was influenced by $\mathrm{N}$ rates for both evaluation periods. Since the height of the plants was influenced by $\mathrm{N}$ rates for the two seasons evaluated. The increased availability of dry per hectare was $87.5 \%$ for the highest $\mathrm{N}$ in the water $\left(333.3 \mathrm{~kg} \mathrm{ha}^{-1} \mathrm{~N}\right.$ ) compared with the control treatment. Nitrogen fertilization positively influences all characteristics related to growth and production mass, especially during the rainy season, when the fertilization must be divided into four or five doses, with no need for fertilization in the dry season.
\end{abstract}

Key Words: morphogenesis, nitrogen fertilization, pastures, tillering

\section{Introdução}

As características morfogênicas e as condições de meio ambiente são os principais fatores que modificam a quantidade de área foliar que interceptará a radiação solar (Lemaire \& Chapmann, 1996; Sousa et al., 2011). Por meio dessas características obtêm-se os parâmetros estruturais da pastagem (tamanho das folhas, número de folhas por perfilhos e densidade populacional de perfilhos) que resultaram na formação do índice de área foliar, ou seja, a área de folhas disponível para interceptar a luz por unidade de área de solo e consequentemente o material verde que será consumido pelos animais em pastejo (Lemaire \& Chapmann, 1996; Cruz \& Boval, 2000; Martuscello, 2009).

A altura, a densidade, as diferentes partes da planta, a composição botânica do dossel e o arranjo espacial são 
fatores que influenciam a ingestão e digestão de plantas forrageiras, e interfere no comportamento ingestivo de bovinos, que tem preferência por partes das estruturas como as folhas em comparação aos caules (Sollenberger \& Burns, 2001). Assim, o arranjo estrutural da planta afetará todas as características de comportamento ingestivo de ruminantes em pastejo (Hodgson, 1985).

Neste contexto, é importante conhecer os fatores do meio que podem causar variações na estrutura da planta e produção de biomassa, principalmente de fatores manipuláveis pelo homem, como é a fertilização com nitrogênio. Objetivou-se neste experimento avaliar o efeito de doses crescente de nitrogênio nas características estruturais e agronômicas da Brachiaria brizantha cv Xaraés sob condições climáticas da região Sul do estado de Mato Grosso.

\section{Material e Métodos}

O experimento foi conduzido na Universidade Federal de Mato Grosso, no Campo Experimental de Forrageiras, em Rondonópolis, Mato Grosso, no período de 12/10/2006 a 23/8/2007. A análise inicial do solo apresentou o seguinte resultado: $\mathrm{pHem} \mathrm{CaCl}_{2}=4,8, \mathrm{P}=1,6 \mathrm{mg} \cdot \mathrm{dm}^{-3}, \mathrm{~K}=22,0 \mathrm{mg} \cdot \mathrm{dm}^{-3}$, $\mathrm{Ca}^{2+}=1,2 \mathrm{cmol}_{\mathrm{C}} \cdot \mathrm{dm}^{-3}, \mathrm{Mg}^{2+}=1,0 \mathrm{cmol}_{\mathrm{C}} \cdot \mathrm{dm}^{-3}, \mathrm{H}+\mathrm{Al}^{3+}=$ $3,5 \mathrm{cmol}_{\mathrm{C}} \cdot \mathrm{dm}^{-3}, \mathrm{Al}^{3+}=0,2 \mathrm{cmol}_{\mathrm{C}} \cdot \mathrm{dm}^{-3}, \mathrm{MO}=15,3 \mathrm{~g} \cdot \mathrm{kg}^{-1}, \mathrm{SB}=$ $2,3 \mathrm{cmol}_{\mathrm{C}} \cdot \mathrm{dm}^{-3}, \mathrm{CTC}=5,8 \mathrm{cmol}_{\mathrm{C}} \cdot \mathrm{dm}^{-3}, \mathrm{~V} \%=39,0 \%$, argila $=$ $400 \mathrm{~g} \cdot \mathrm{kg}^{-1}$, silte $=100 \mathrm{~g} \cdot \mathrm{kg}^{-1} \mathrm{e}$ areia total $=500 \mathrm{~g} \cdot \mathrm{kg}^{-1}$. Os dados climáticos (Figura 1) foram coletados na Estação Meteorológica do Departamento de Geografia da UFMT, distante $400 \mathrm{~m}$ da área experimental.

As adubações foram realizadas de acordo com recomendações de Ribeiro et al. (1999). A adubação fosfatada foi distribuída manualmente no momento do plantio, na quantidade de $100 \mathrm{~kg} \cdot \mathrm{ha}^{-1} \mathrm{de}_{2} \mathrm{O}_{5}$ na forma de superfosfato simples. As adubações nitrogenadas e potássicas foram divididas em seis aplicações, sendo quatro no período chuvoso, uma no período de transição águas/seca e a última no período seco (Tabela 1). O potássio (K) foi distribuído na quantidade de $300 \mathrm{~kg}$.ha ${ }^{-1} \mathrm{de}_{2} \mathrm{O}$ na forma de cloreto de potássio (KCl).

Foram implantadas 20 parcelas de capim-xaraés, com área útil de $12 \mathrm{~m}^{2}$, sendo a semeadura realizada em linhas no dia 23/12/05. Os tratamentos consistiram de cinco doses de $\mathrm{N}:$ 0, 125, 250, 375 e $500 \mathrm{~kg}^{-h a^{-1}}$ de N, utilizando-se como fonte de $\mathrm{N}$, a ureia (45\% de $\mathrm{N}$ ). O delineamento experimental utilizado foi o inteiramente casualizado, com quatro repetições.

A cada 35 dias durante o período das águas e 70 dias durante o período da seca, realizou-se o corte com cutelo a
$23 \mathrm{~cm}$ acima do nível do solo em todas as parcelas, sendo sete cortes ao longo do período experimental (Tabela 1).

Foram avaliadas as seguintes características estruturais e agronômicas: número de folhas aparecidas.perfilho ${ }^{-1}$ (NFA), número de folhas vivas.perfilho ${ }^{-1}$ (NFV), número de folhas totais.perfilho ${ }^{-1}$ (NFT), comprimento médio de lâmina foliar (CMLF), densidade populacional de perfilhos (DPP), altura média de plantas (AL), disponibilidade total de matéria seca (DTMS) e composição morfológica dos perfilhos, relação lâmina foliar:colmo (RLC) e índice de área foliar (IAF).

Um dia antes de cada corte, no período vespertino, foram realizadas as medições da DPP e da AL. Para avaliação da DPP foi utilizado um quadro de amostragem de $1,00 \times 0,15 \mathrm{~m}$, o qual foi alocado em local que representasse a altura média das plantas das parcelas, procedendo-se em seguida à contagem dos perfilhos contidos dentro do quadro.

Os dados de CMLF, NFA, NFV e NFT foram registrados em planilhas de avaliações morfogênicas e, ao final de cada ciclo, obteve-se a média de cada variável para o período estudado, 35 dias nas águas e 70 dias no período seco. No NFA foram consideradas as folhas que apareceram e cessaram seu crescimento por meio da exposição de sua lígula, caracterizando o término de seu crescimento foliar dentro do período de avaliação. O NFV por perfilho foi calculado a partir do número médio de folhas em expansão e completamente expandidas, desconsiderando as folhas senescentes e o NFT, pelo número total de folhas de cada perfilho, considerando folhas vivas e senescentes existentes dentro do período de avaliação.

A altura média do dossel (AL) foi determinada utilizando-se uma régua graduada, sendo medidos 20 pontos aleatórios por unidade experimental. A medida da altura de cada ponto correspondeu à altura média das plantas em torno da régua. Essas leituras eram realizadas na inflexão média das folhas mais altas das touceiras.

$\longrightarrow$ Pluviosidade $\longrightarrow$ Temperatura mínima - Temperatura máxima $\longrightarrow$ Temperatura média

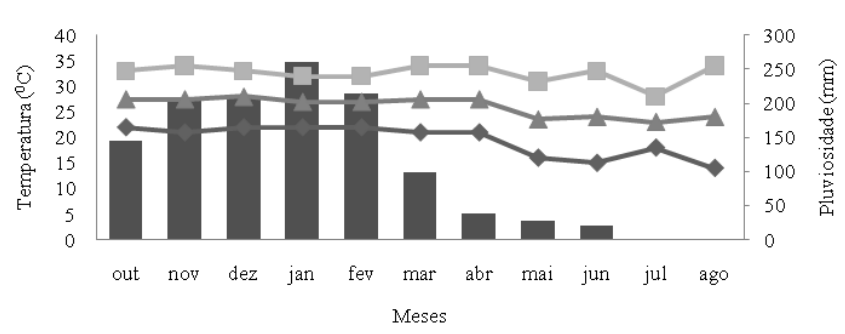

Figura 1 - Temperaturas médias e pluviosidade mensal durante o período experimental (outubro de 2006 a agosto de 2007). 
Tabela 1 - Intervalo de cortes e distribuição das doses de $\mathrm{N}\left(\mathrm{kg}_{\mathrm{gha}}{ }^{-1}\right)$ ao longo do período experimental

\begin{tabular}{|c|c|c|c|c|c|c|c|}
\hline Corte & $1^{\circ}$ & $2^{\circ}$ & $3^{\circ}$ & $4^{\circ}$ & $5^{\circ}$ & $6^{\circ}$ & $7^{\circ}$ \\
\hline Data & $16 / 11 / 06$ & $21 / 12 / 06$ & $25 / 01 / 07$ & $01 / 03 / 07$ & $05 / 04 / 07$ & $14 / 06 / 07$ & $23 / 08 / 07$ \\
\hline Doses/Intervalo & - & 35 & 35 & 35 & 35 & 70 & 70 \\
\hline 0 & 0 & 0 & 0 & 0 & 0 & 0 & 0 \\
\hline 125 kg.ha-1 de $\mathrm{N}$ & 20,83 & 20,83 & 20,83 & 20,83 & 20,83 & 20,83 & 0 \\
\hline 250 kg.ha ${ }^{-1}$ de $N$ & 41,66 & 41,66 & 41,66 & 41,66 & 41,66 & 41,66 & 0 \\
\hline 375 kg.ha-1 de $\mathrm{N}$ & 62,50 & 62,50 & 62,50 & 62,50 & 62,50 & 62,50 & 0 \\
\hline 500 kg.ha-1 de $\mathrm{N}$ & 83,33 & 83,33 & 83,33 & 83,33 & 83,33 & 83,33 & 0 \\
\hline
\end{tabular}

A disponibilidade total de matéria seca do capimxaraés foi mensurada pelo método de amostragem direta, com o uso de um quadro de amostragem de 1,00 ×0,60 m, colocado na altura média das plantas da parcela. Toda a forragem contida no interior do quadro foi cortada a $23 \mathrm{~cm}$ acima do nível do solo e posteriormente colocado em sacos previamente identificados e encaminhado para laboratório para determinação da disponibilidade de MS, composição morfológica dos perfilhos e do índice de área foliar.

Após pesagem das amostras provenientes de cada parcela foram retiradas duas subamostras por parcela, uma para quantificar a MS da forragem e a outra para quantificar a proporção de lâmina foliar, colmo (colmo + pseudocolmo) e material senescente. Em seguida as amostras foram pesadas em balança semianalítica, e seca em estufa de circulação e renovação forçada de ar a $60{ }^{\circ} \mathrm{C}$ durante 72 horas.

Foram calculados também os valores médios da densidade volumétrica da forragem $\left(\mathrm{kg} \cdot \mathrm{ha}^{-1} \cdot \mathrm{cm}^{-1}\right)$, sendo a massa seca de forragem dividida pela altura média correspondente do pasto, descontado $23 \mathrm{~cm}$, referentes à altura do corte. Os valores de DTMS foram convertidos para kg.ha- ${ }^{-1}$ de MS e os componentes morfológicos expressos como proporção (\%) da massa seca de forragem e kg.ha-1 de MS. A relação folha/colmo foi obtida a partir do quociente entre massa seca de folhas e a massa seca de colmo.

Outra alíquota foi utilizada para determinação do IAF, conforme metodologia descrita por Alexandrino et al. (2005). Deste modo, para realização do cálculo do IAF das parcelas, foram separadas lâminas foliares totalmente expandidas e intactas, a qual foi completamente seccionada, a partir de sua base, em frações de $10 \mathrm{~cm}$, até a totalização de 150 pedaços de $10 \mathrm{~cm}$ de comprimento cada. Em seguida, mediu-se a largura média das 150 frações, somando-se os valores.

Obteve-se a estimativa do IAF de cada tratamento por meio da seguinte fórmula:

$I A F=\left\{\left[P L F V *(S L * 100) / P_{150}\right] * 1 / A Q / 10^{6}\right\}$

em que PLFV = peso, em gramas, de lâmina foliar verde, obtido pelo método do quadrado; $\mathrm{SL}=$ soma das larguras das 150 frações de $10 \mathrm{~cm} ; \mathrm{P}_{150}=$ peso das 150 frações, em gramas; $\mathrm{AQ}=$ área do quadrado utilizado $\left(0,60 \mathrm{~m}^{2}\right)$.

Os resultados foram agrupados de acordo com as épocas do ano. No período das águas, foram compreendidos os quatros primeiro cortes (doses acumuladas de: $0,83,3$, 166,6, 249,9 e 333,3 kg.ha-1 de N). A outra avaliação considerou o comportamento da gramínea ao longo do ano, considerando todos os sete cortes com o nível acumulado de adubação completo $\left(0,125,250,375\right.$ e 500 kg.ha $^{-1}$ de N).

Para avaliar o efeito dos cortes e da adubação nitrogenada sobre as características estruturais do capimxaraés no período das águas ou no período total, foram utilizadas análises de covariância com medidas repetidas na mesma unidade experimental (parcela). O efeito do corte foi considerado classificatório e o efeito linear e quadrático das doses de nitrogênio foram as covariáveis.

O erro foi considerado efeito aleatório e a estrutura de covariância do tipo Auto-regressiva Heterogênea de Primeira Ordem foi utilizada para modelar a estrutura de covariância residual. Esta estrutura foi escolhida porque foi aquela que melhor se ajustou aos dados disponíveis de acordo com os critérios -2RLL (valor da função de verossimilhança restrita), AIC (Critério de Informação de Akaike) e CAIC (Critério de Informação de Akaike Consistente). Um efeito foi considerado estatisticamente significativo quando o nível de significância foi de 0,10 , no máximo. As análises estatísticas foram realizadas utilizando-se o procedimento MIXED do SAS (Statistical Analysis System, versão 8.2).

\section{Resultados e Discussão}

O número de folhas aparecidas por perfilho foi influenciado $(\mathrm{P}<0,001)$ pelas doses de $\mathrm{N}$ no período chuvoso e ao longo do ano (Figura 2). No período das águas, apresentou comportamento quadrático em resposta às doses de $\mathrm{N}$ aplicada, com valor de 1,64 folhas.perfilho- ${ }^{-1}$. período $^{-1}$, obtido com adição de 293,0 kg.ha-1 de $\mathrm{N}$. Nesse período, os valores estimados variaram de 0,99 a 
1,62 folhas.perfilho-1 .período $^{-1}$ para as doses de 0 a 333,3 kg.ha-1 de N, respectivamente.

Para o período anual, apenas o efeito linear foi estatisticamente significativo para o nível de significância de $1 \%$. Os valores estimados variaram de 0,9 a 1,03 folhas.perfilho ${ }^{-1}$.período $^{-1}$ para as doses de 0 a $500 \mathrm{~kg} . \mathrm{ha}^{-1} \mathrm{de} \mathrm{N}$. Ao longo do ano, a maior quantidade de folhas surgidas foi obtida para a mais elevada dose de N, havendo um acréscimo de $14 \%$ no NFA para o tratamento de 500 kg.ha ${ }^{-1}$ de $\mathrm{N}$ em comparação à ausência de $\mathrm{N}$.

Observou-se efeito $(\mathrm{P}<0,01)$ das doses de $\mathrm{N}$ no comportamento do NFV somente para o período chuvoso (Figura 3).

O número de folhas vivas.perfilho- ${ }^{-1}$ varia em função das características do ambiente e do manejo, como as condições hídricas do solo (Mattos et al., 2005; Silva et al., 2005), a adubação nitrogenada (Pilbeam, 1992; GarcezNeto et al., 2002; Alexandrino et al., 2004), além de outros fatores (Martuscello, 2009; Sousa et al., 2011). O

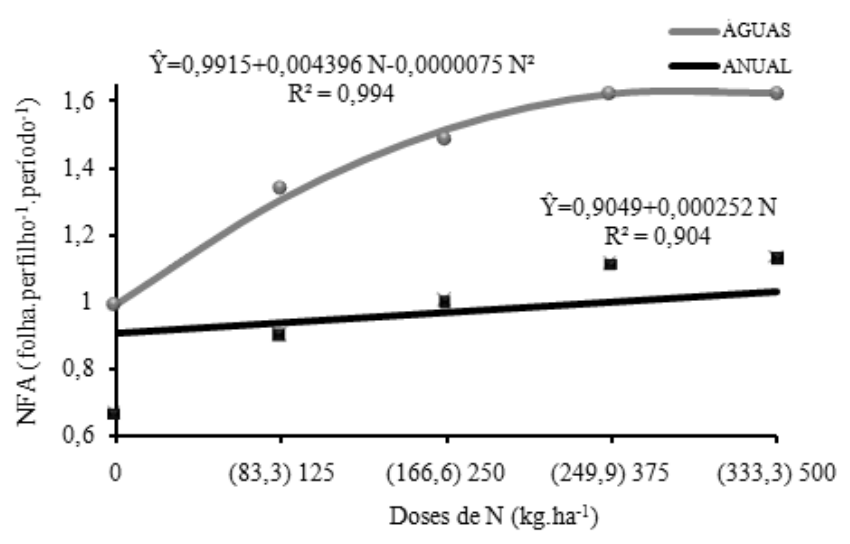

Figura 2 - Estimativa do número médio de folhas aparecidas do capim-xaraés durante o período das águas e anual em função das doses de $\mathrm{N}\left(\mathrm{kg} \cdot \mathrm{ha}^{-1}\right)$.

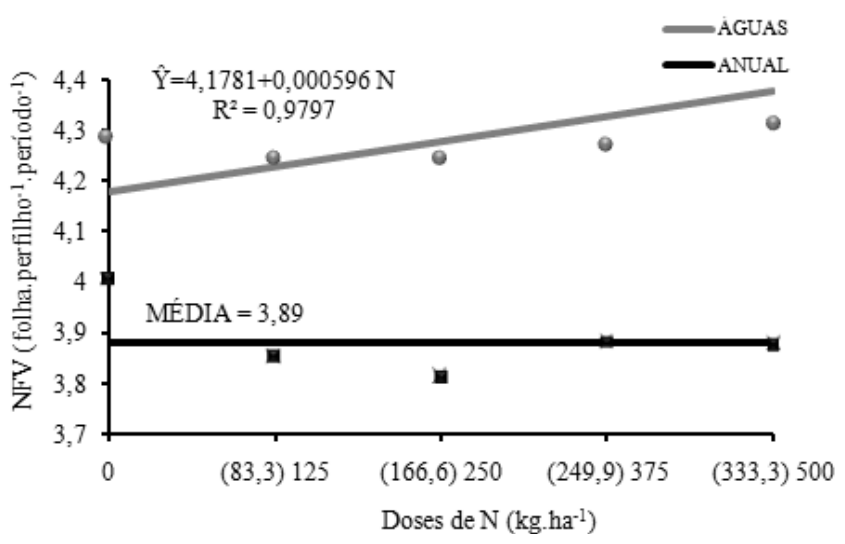

Figura 3 - Estimativa do número médio de folhas verdes do capimxaraés durante o período das águas e ao longo do ano em função das doses de $\mathrm{N}\left(\mathrm{kg} \cdot \mathrm{ha}^{-1}\right)$.
NFV foi incrementado linear e positivamente conforme se acrescentaram as doses de $\mathrm{N}$, sendo que a dose de $333,3 \mathrm{~kg} \cdot \mathrm{ha}^{-1}$ possibilitou a manutenção de 4,38 folhas verdes.perfilho ${ }^{-1}$. período $^{-1}$ nas águas.

Não houve efeito significativo $(\mathrm{P}>0,10)$ dos níveis de $\mathrm{N}$ sobre o NFV ao longo do ano, sendo obtida a média de 3,89 folhas verdes.perfilho ${ }^{-1}$.período ${ }^{-1}$. Estes valores estão bem próximos àqueles encontrados por Martuscello et al. (2005), que observaram influência da adubação nitrogenada e das desfolhações sobre o NFV, obtendo-se 4,73; 4,58 e 4,34 folhas vivas para os corte com duas, quatro e cinco folhas completamente expandidas para o capim-xaraés submetido a adubação com $\mathrm{N}$ e desfolhações.

O NFT foi influenciado pela adubação nitrogenada no período das águas $(\mathrm{P}<0,005)$ e no período anual $(\mathrm{P}<0,10)$ de avaliação (Figura 4). Para o período das águas, estimou-se máximo valor de 6,13 folhas totais.perfilho ${ }^{-1}$.período ${ }^{-1}$ para a dose de 293,9 kg.ha-1 de N. A partir desta dose, o incremento em folhas.perfilho ${ }^{-1}$ exigiu maior acréscimo nos níveis de $\mathrm{N}$, diminuindo a eficiência de uso da adubação.

No período anual, o efeito das doses de $\mathrm{N}$ ajustaram-se a modelos quadráticos, estimando-se o valor de 5,26 folha.perfilho ${ }^{-1}$ para a dose de $335,4 \mathrm{~kg} \mathrm{ha}^{-1} \mathrm{de} \mathrm{N}$, sendo o NFT para o tratamento testemunha de 4,97 folha.perfilho ${ }^{-1}$. $\mathrm{O}$ intenso fluxo de tecido ocasionado por elevadas doses de $\mathrm{N}$ nos tecidos meristemáticos possibilitou maiores taxas de alongamento e aparecimento foliares nas plantas, permitindo maior número de folhas no perfilho.

Avaliando o comprimento médio de lâmina foliar $(\mathrm{CMLF})$ verificou-se efeito $(\mathrm{P}<0,05)$ da adubação nitrogenada para as duas épocas avaliadas (Figura 5). Os dados gerados pela equação estão em mm, no entanto para comparação e

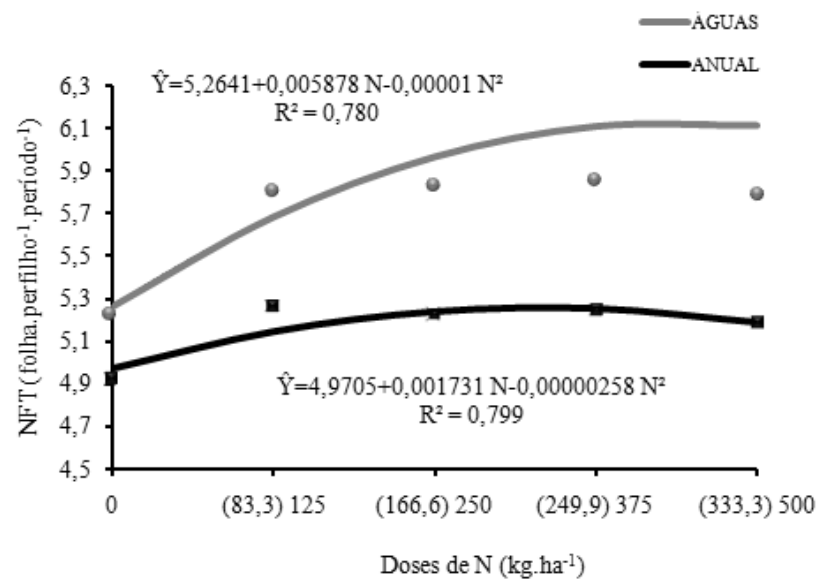

Figura 4 - Estimativa do número de folhas totais do capim-xaraés durante o período das águas e anual em função das doses de $\mathrm{N}\left(\mathrm{kg}^{\mathrm{hah}}{ }^{-1}\right)$. 
compreensão do comportamento do capim-xaraés, os dados estão apresentados em cm ao longo da discussão. O ponto de máxima foi estimado em 28,24 e 24,30 cm.lâmina foliar ${ }^{-1}$ para a dose de 343,9 e 591 kg.ha-1 de $\mathrm{N}$ para o período das águas e ao longo do ano, respectivamente.

A partir dos valores de máxima estimados, pode-se inferir que o uso de $\mathrm{N}$ poderia aumentar em 27 e $25 \%$ no CMLF quando comparada a gramínea não adubada no período das águas e no período anual de avaliação, respectivamente. No entanto, o valor do tamanho máximo da lâmina foliar para as duas épocas avaliadas não foi observado, pois as doses de máximas estimadas são maiores que a dose máxima utilizada no estudo.

Para as maiores doses estudadas, 333,3 e 500 kg.ha ${ }^{-1}$ de $\mathrm{N}$, a adubação nitrogenada proporcionou aumento de $27 \mathrm{e}$ 24,5\% no CMLF quando comparada a gramínea não adubada para as duas épocas avaliadas, respectivamente. Desse modo, deve-se dar atenção especial ao nível de $\mathrm{N}$ como estimulante do crescimento da planta forrageira, tendo em vista sua grande contribuição para o tamanho final das lâminas foliares, aumentando o alongamento foliar e a interceptação de radiação solar, por meio da maximização da área foliar fotossinteticamente ativa.

Martuscello et al. (2006), avaliando o capim-massai sob adubação nitrogenada e desfolhação concluíram que o comprimento final da lâmina foliar (CFL) respondeu $(\mathrm{P}<0,05)$ tanto à adubação nitrogenada quanto à frequência de corte, porém com efeito muito mais acentuado da adubação nitrogenada.

O aumento no tamanho de lâmina em relação aos tratamentos pode ser explicado pelo efeito simultâneo

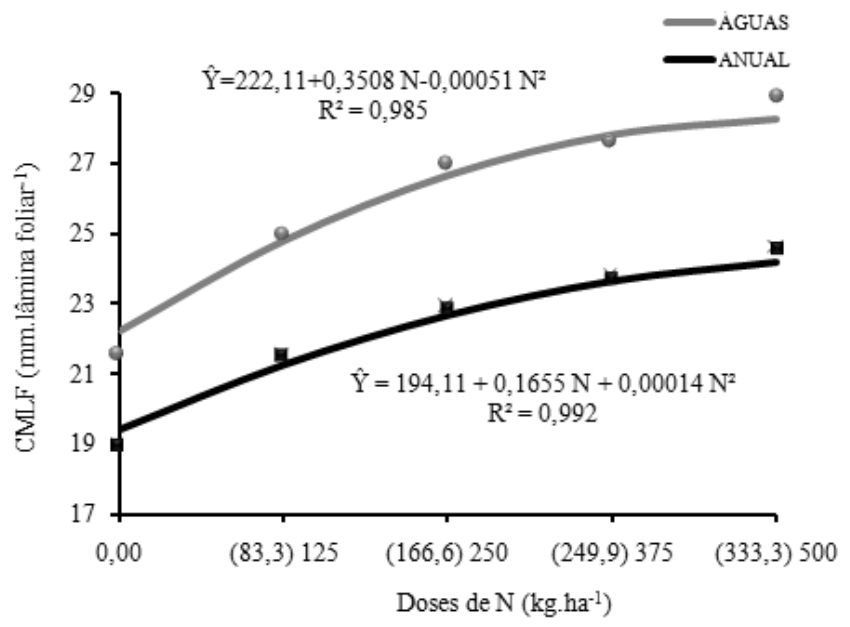

Figura 5 - Estimativa do comprimento médio de lâmina foliar do capim-xaraés durante o período das águas e anual em função das doses de $\mathrm{N}\left(\mathrm{kg} \cdot \mathrm{ha}^{-1}\right)$. do $\mathrm{N}$, que aumenta de forma expressiva o número de células em processo de divisão, definindo maior comprimento da bainha que a lâmina em expansão terá que percorrer. O nitrogênio, ao estimular a produção denovas células, possibilita aumento na taxa de alongamento de folhas, o que pode constituir meio para mudanças no tamanho da lâmina foliar.

Verificou-se efeito quadrático $(\mathrm{P}<0,0001)$ das doses de N sobre a DPP em ambos os período de avaliação (Figura 6), estimando-se máximo valor de 113 e 110 perfilhos.0,15 ${ }^{-2}$ para as doses de 270 e $401 \mathrm{~kg}^{-h^{-1}}{ }^{-1 e} \mathrm{~N}$, respectivamente. O aumento na DPP foi de 89 e $87 \%$ em relação ao capim não adubado no período das águas e na avaliação anual, respectivamente.

A produção de massa por perfilho é dependente da taxa de aparecimento de folhas, da taxa de alongamento de folhas, do tamanho final da folha e da duração de vida das folhas. No entanto, a produção de massa por área e a estrutura da pastagem dependem da densidade de perfilhos no pasto. Daí, a importância de se estudar essa característica, por estar diretamente relacionada à disponibilidade total de matéria seca de forragem e ao consumo animal.

A eficiência de uso da adubação nitrogenada para os dois períodos avaliados foi de 0,19 perfilho. $0,15 \mathrm{~m}^{-2}$ (270 kg.ha-1 de N) e 0,12 perfilho.0, $15 \mathrm{~m}^{-2}$ (401 kg.ha- ${ }^{-1}$ de N) para cada kg de $\mathrm{N}$ utilizado, nas águas e ao longo do ano, respectivamente. Para as parcelas não adubadas, a DPP do capim-xaraés ao longo do ano foi limitada e constante, em média 58,9 perfilhos. $0,15 \mathrm{~m}^{-2}$.

Após os pontos de máximas das duas épocas avaliadas, houve decréscimo na DPP, pelo fato de as maiores doses terem incrementado a taxa de alongamento foliar, permitindo

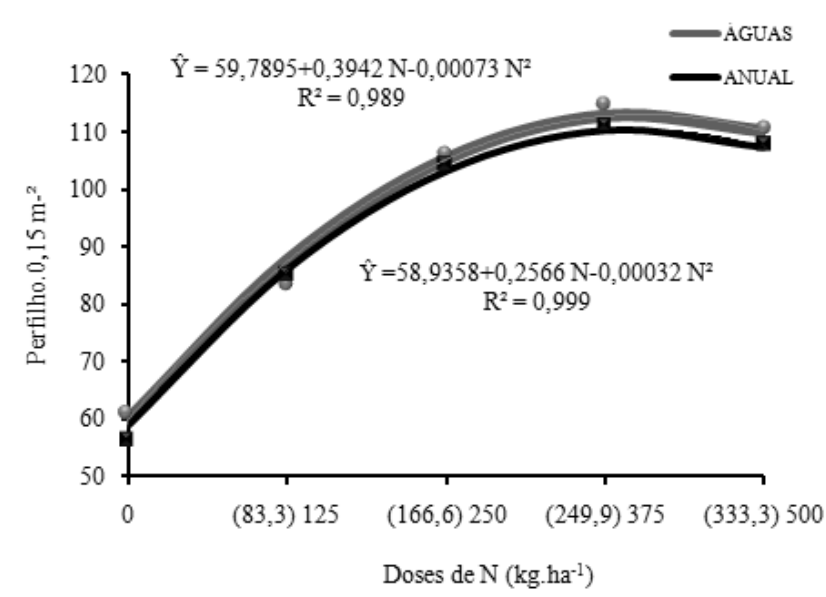

Figura 6 - Estimativa da densidade populacional de perfilhos do capim-xaraés durante o período das águas e anual em função das doses de $\mathrm{N}\left(\mathrm{kg} \cdot \mathrm{ha}^{-1}\right)$. 
que a comunidade de plantas obtivesse maior altura e índice de área foliar, gerando competição por luz entre perfilhos, diminuindo assim a luminosidade na base dos perfilhos, que é reconhecidamente um dos fatores que podem interferir na capacidade de perfilhamento de gramíneas tropicais. Vários dados disponíveis na literatura indicam decréscimo na população de perfilhos à medida que os pastos são mantidos mais altos (Hodgson, 1985; Sbrissia \& Da Silva, 2001; Sbrissia, 2004).

Nabinger (1996) afirmou que o déficit de $\mathrm{N}$ aumenta o número de gemas dormentes, enquanto o suprimento permite o máximo perfilhamento. Garcez Neto et al. (2002) também verificaram efeito expressivo do suprimento de $\mathrm{N}$ no número total de perfilhos (21\% na densidade populacional de perfilhos). Segundo esses autores, o perfilhamento em gramíneas é uma característica estrutural determinante da plasticidade morfogênica das plantas forrageiras influenciada por combinações de fatores nutricionais, ambientais e de manejo sobre características morfogênicas.

Em relação ao comportamento da altura média das plantas (AL) nos períodos avaliados, observou-se efeito significativo $(\mathrm{P}<0,0005)$ das doses de $\mathrm{N}$ nas águas e ao longo do ano (Figura 7). Assim, decompondo os efeitos dos níveis de $\mathrm{N}$ em efeitos linear e quadrático, observou-se que a dispersão dos dados adequou-se melhor à distribuição polinomial quadrática.

Derivando-se as equações de regressão, observou-se que os valores de máxima altura, 64 e $53 \mathrm{~cm}$ foram obtidos com as doses de 280,5 e 407,5 kg.ha ${ }^{-1}$ de N, respectivamente. EM análise da eficiência de uso do $\mathrm{N}$ na determinação da altura do capim-xaraés, a partir do ponto de máxima em comparação a ausência de N, observou-se incremento na

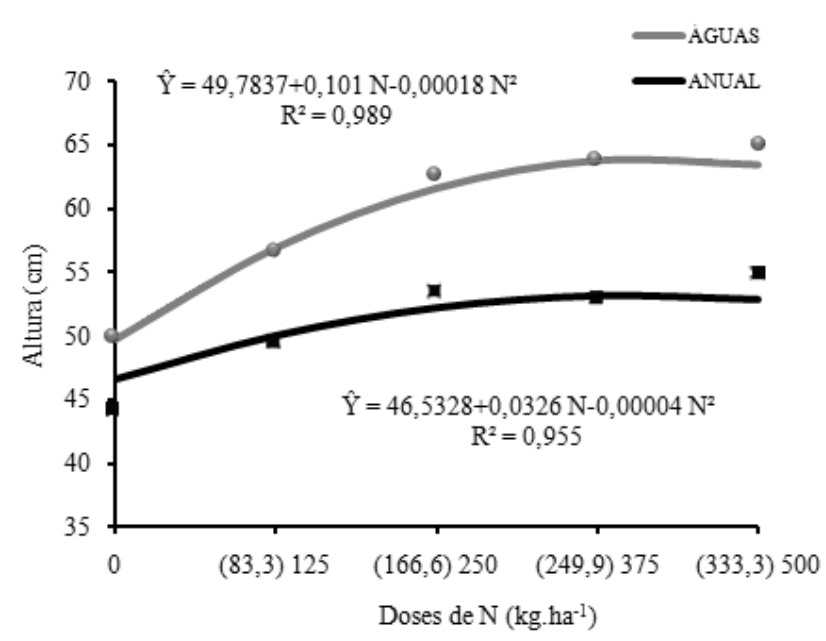

Figura 7 - Estimativa da altura média de plantas do capim-xaraés durante o período das águas e anual em função das doses de $\mathrm{N}\left(\mathrm{kg} \cdot \mathrm{ha}^{-1}\right)$.
AL de 0,050 cm nas águas e de $0,016 \mathrm{~cm}$ ao longo do ano para cada kg de $\mathrm{N}$ aplicado.

Aumentos na altura de plantas forrageiras têm sido acompanhados por redução na relação folha/colmo (Almeida et al., 2000; Gomide, 2001) devido ao aumento no alongamento de colmo (Santos, 2003). Comparando-se o ponto de máxima altura nas águas com a ausência de $\mathrm{N}$ $(\mathrm{AL}=49,7 \mathrm{~cm})$, a adubação nitrogenada incrementou em 28\% a AL do capim-xaraés. Resultado semelhante foi obtido para o período anual, quando o incremento em relação à ausência da adubação nitrogenada $(\mathrm{AL}=46,53 \mathrm{~cm})$ foi de 14\% na AL do capim-xaraés. Hodgson (1990) citou que há evidências de que medidas de altura fornecem a melhor indicação da produção de forragem e desempenho do animal em circunstâncias particulares, e padrões mais consistentes de respostas sob diferentes condições.

As características estruturais contribuem para determinar a disponibilidade de massa e o acesso a forragem por animais em pastejo, afetando o comportamento ingestivo. A disponibilidade total de matéria seca e a composição morfológica dos perfilhos em função das doses de $\mathrm{N}$ foram analisadas somente no período chuvoso do ano, quando as respostas do capim-xaraés à adubação nitrogenada foram mais intensivas. Assim, ao avaliar o comportamento da disponibilidade total de matéria seca (DTMS) nas águas, em função da adubação nitrogenada, verificou-se efeito quadrático $(\mathrm{P}<0,05)$ para a DTMS (Figura 8).

Após a derivação da equação de regressão, observou-se que o ponto de máxima para a DTMS seria alcançado mediante dose superior à dose máxima utilizada nesse estudo, quando a dose de $385 \mathrm{~kg} \cdot \mathrm{ha}^{-1}$ de $\mathrm{N}$, possibilitaria a disponibilidade total de 6,29 t.ha-1 de MS, 89\% maior

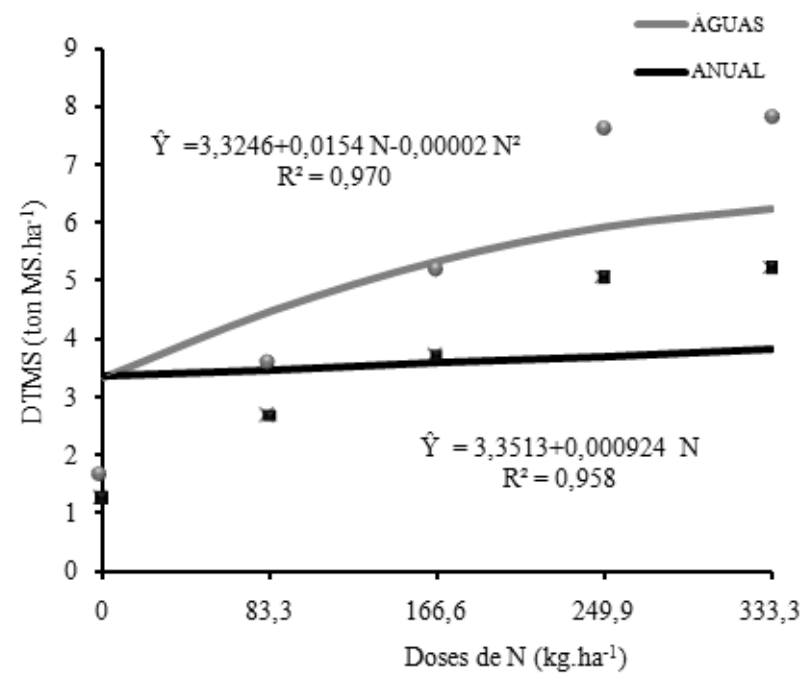

Figura 8 - Estimativa da disponibilidade total de matéria seca do capim-xaraés durante o período das águas e anual em função das doses de $\mathrm{N}\left(\mathrm{kg} \cdot \mathrm{ha}^{-1}\right)$. 
comparada à ausência de $\mathrm{N}$ e a densidade volumétrica de $161,5 \mathrm{~kg} \cdot \mathrm{ha}^{-1} \cdot \mathrm{cm}^{-1}$ de MS. No entanto, para a maior dose utilizada no estudo (333,3 kg.ha-1 de N), a DTMS foi de 6,24 t.ha-1 de MS e densidade volumétrica de $154,26 \mathrm{~kg} \cdot \mathrm{ha}^{-1} \cdot \mathrm{cm}^{-1}$ de MS, a qual foi acumulada em crescimento livre dentro do intervalo de 35 dias, podendo-se a partir daí inferir que houve o acúmulo de forragem de 178,28 kg.ha-1 dia $^{-1}$ de MS no período das águas. O aumento na DTMS foi de 87,5\% para a maior dose de N em comparação ao tratamento testemunha $\left(3,32\right.$ t.ha $^{-1}$ de MS; densidade volumétrica de $124 \mathrm{~kg} \cdot \mathrm{ha}^{-1} . \mathrm{cm}^{-1}$ de MS), sendo a eficiência de uso do $\mathrm{N}$ convertida em 8,73 kg.ha-1 de MS para cada $\mathrm{kg}$ de $\mathrm{N}$ aplicado.

Na ausência de $\mathrm{N}$ a DMSLFV foi limitada, no entanto, conforme se aumentou a disponibilidade de $\mathrm{N}$, ocorreram incrementos significativos $(\mathrm{P}<0,005)$ para essa variável (Figura 9) e a dispersão dos dados adequou-se melhor a uma distribuição polinomial quadrática.

Do mesmo modo que ocorrido com a DTMS, após a derivação da equação de regressão, observou-se que o ponto de máxima para a DMSLFV seria alcançado mediante dose superior à máxima utilizada no experimento, com o ponto de máxima de $356 \mathrm{~kg}$ ha $^{-1}$ de $\mathrm{N}$ com disponibilidade de lâminas foliares de 4,09 t.ha ${ }^{-1}$ de MS, acúmulo de $117 \mathrm{~kg} \cdot \mathrm{ha}^{-1} \cdot \mathrm{dia}^{-1}$ de MS e densidade volumétrica de 102,4 kg.ha- ${ }^{-1} \cdot \mathrm{cm}^{-1}$ de MS de lâmina foliar. Comparando-se a maior dose de $\mathrm{N}$ com a ausência da adubação nitrogenada (1,56 ton.ha ${ }^{-1}$ de MS), observa-se aumento de $162 \%$ na DMSLFV, com eficiência de uso de 7,5 kg.ha ${ }^{-1}$ de MS para cada kg de $\mathrm{N}$ utilizado. Flores et al. (2008) avaliando as características estruturais e de produção do capim-xaraés submetidos a três intensidades de pastejo (15, 30 e 45 cm de altura do dossel) encontraram a disponibilidade de 590,0;

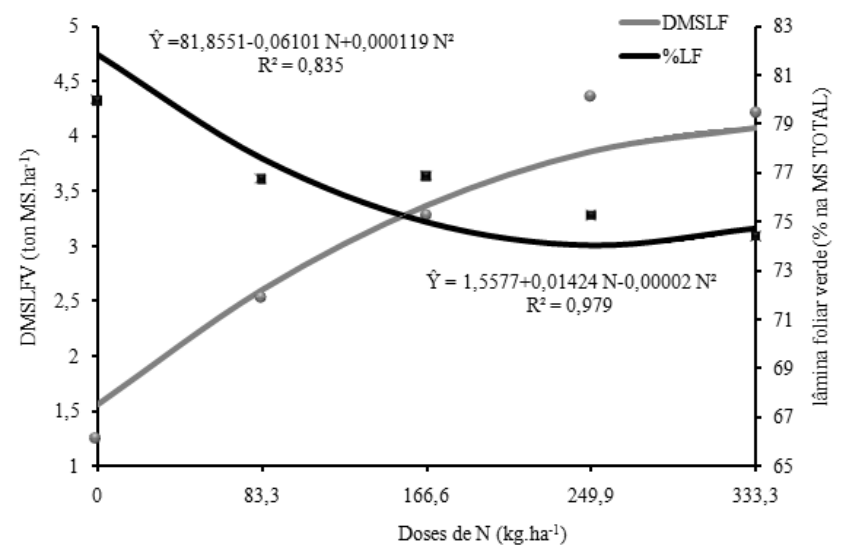

Figura 9 - Estimativa da disponibilidade total de lâmina foliar verde e participação na matéria seca total do capimxaraés durante o período das águas em função das doses de $\mathrm{N}\left(\mathrm{kg}_{\mathrm{ha}} \mathrm{ha}^{-1}\right)$
740,0; e 1.505,0 kg.MS.ha e taxa de acúmulo diário de 75,1; 90,7; 120,4 kg.MS.dia para respectivas alturas.

A análise de regressão comprovou efeito quadrático $(\mathrm{P}<0,01)$ das doses de $\mathrm{N}$ para a porcentagem de lâmina foliar, estimando-se mínimo valor de 74\% para a dose de 256,3 kg.ha-1 de N. Essa redução ocorre devido à maior participação de colmo com adição de $\mathrm{N}$ nas parcelas, sendo que, na ausência de $\mathrm{N}$ a lâmina foliar, perfazia $82 \%$ da composição total dos perfilhos, assim, para cada $50 \mathrm{~kg}$ ha $^{-1}$ de $\mathrm{N}$ aplicado, ocorreu redução de 1,2\% de lâmina foliar na DTMS. O percentual de queda da lâmina foliar na composição da matéria seca total, quando comparado ao tratamento testemunha com a maior dose de $\mathrm{N}$ (333,3 kg.ha-1 de N), foi de 9,6\%.

O estudo da regressão detectou efeito quadrático das doses de $\mathrm{N}$ sobre a disponibilidade de matéria seca de colmo (DMSCOL, $\mathrm{P}<0,005)$ e sobre a \%COL $(\mathrm{P}<0,005)$ (Figura 10 ). De acordo com a equação obtida para DMSCOL, o valor máximo de 1,13 t.ha ${ }^{-1}$ será obtido para uma dose de 412,5 kg.ha ${ }^{-1}$ de N, ou seja, superior à dose máxima utilizada durante as águas.

A densidade volumétrica foi de 29,87 kg.ha- ${ }^{-1} . \mathrm{cm}^{-1}$ de MS, com acúmulo de 32,28 kg.ha ${ }^{-1}$. dia ${ }^{-1}$ de MS. Para a maior dose utilizada no estudo (333,3 kg.ha-1 de N), a DMSCOL foi de 1,10 t.ha ${ }^{-1}$ de MS, com acúmulo de 31,4 kg.ha ${ }^{-1} \cdot$ dia $^{-1}$ de MS e densidade volumétrica de 27,19 kg.ha- ${ }^{-1} \cdot \mathrm{cm}^{-1}$ de MS de colmo. Comparativamente à ausência de $\mathrm{N}$, a maior dose apresentou incremento de $435 \%$ na DMSCOL, com eficiência de uso do N de 2,68 kg.ha ${ }^{-1}$ de MS para cada kg de N aplicado.

A participação de colmo na matéria seca total mudou com a adição de N, obtendo-se máximo valor de $26,7 \%$ de colmo com a dose de 275,18 kg.ha-1 de N. Na ausência de N, a proporção do colmo perfez $21 \%$ da composição total dos perfilhos, assim para cada 50 kg.ha ${ }^{-1}$ de $\mathrm{N}$ aplicado,

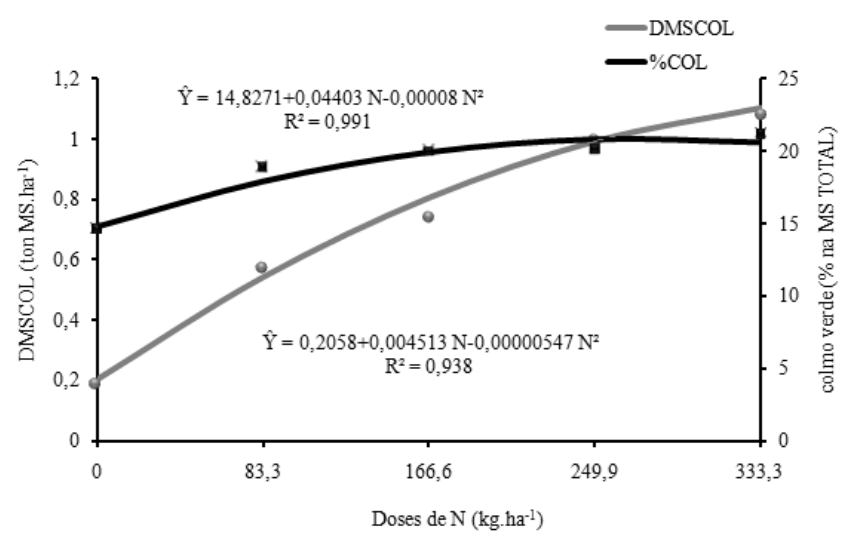

Figura 10 - Estimativa da disponibilidade total de colmo do capimxaraés durante o período das águas em função das doses de $\mathrm{N}\left(\mathrm{kg}_{\mathrm{hga}}{ }^{-1}\right)$. 
ocorreu incremento de $0,90 \%$ de colmo na DTMS. O tratamento testemunha apresentou $28 \%$ a menos o componente colmo na DTMS quando comparado à maior dose de $\mathrm{N}$ aplicada (333,3 kg.ha- ${ }^{-1}$ de $\mathrm{N}$ ).

O desenvolvimento de colmos incrementou a produção de matéria seca, mas, em contrapartida, interferiu na estrutura do dossel, apresentando efeitos negativos sobre a qualidade da forragem por meio da redução na relação lâmina:colmo, característica que guarda relação direta com o desempenho dos animais em pastejo (Euclides et al., 2000).

A disponibilidade total de material morto (DTMM) variou $(\mathrm{P}<0,062)$ conforme se aumentaram os níveis de $\mathrm{N}$ aplicados. Assim, após avaliação por meio de análise de regressão e polinômios ortogonais, verificou-se efeito de tendência quadrática para a DTMM com o aumento das doses de nitrogênio (Figura 11).

A adubação nitrogenada, quando aplicada durante o período das águas, aumentou a deposição de material morto do capim-xaraés, cujo valor foi de $416 \mathrm{~kg} \mathrm{ha}^{-1}$ de MS para a dose de 295,60 kg.ha-1 de N, consequência do acúmulo de diário de 11,88 kg.ha ${ }^{-1}$.dia-1 de MS e densidade volumétrica de 10,16 kg.ha-1 .cm $^{-1}$ de MS de MM. Na ausência de N, a DTMM foi de $157 \mathrm{~kg}^{-h^{-1}}$ de MS, 62\% menos que a obtida na maior dose de N aplicada (333,3 kg.ha-1 de N). Deste modo, pode-se determinar que, para cada kg de $\mathrm{N}$ aplicado, haverá um aumento de $0,763 \mathrm{~kg} \cdot \mathrm{ha}^{-1}$ de MS de material morto. Decompondo-se os efeitos da adubação nitrogenada sobre a \%MM em efeito linear e quadrático, observou-se que apenas o efeito linear foi estatisticamente significativo para o nível de significância de $1 \%$.

Dessa forma, conforme se aumentaram as doses de $\mathrm{N}$, a participação de material morto na matéria seca total respondeu linearmente, atingindo 5,3\% na DTMS na dose de 333,3 kg.ha- ${ }^{-1}$ de $\mathrm{N}$. Na ausência de N, a proporção de material morto totalizou $3,9 \%$ da composição total dos

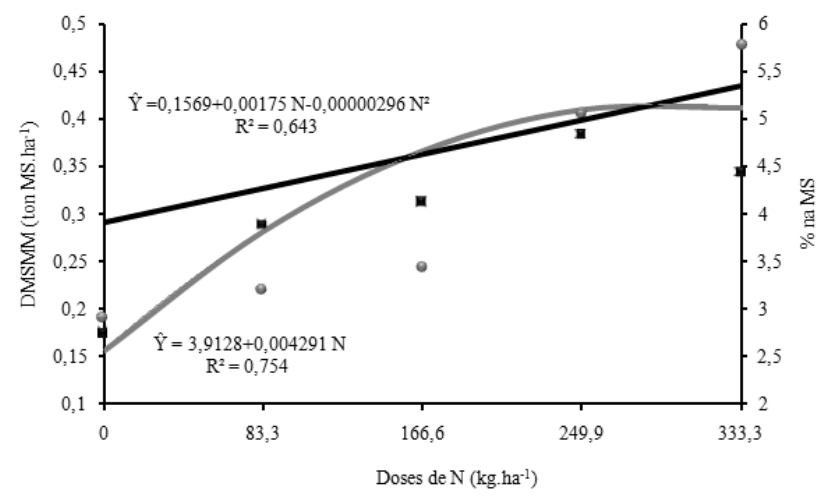

Figura 11 - Estimativa da disponibilidade total de material morto do capim-xaraés durante o período das águas em função das doses de $\mathrm{N}\left(\mathrm{kg} \cdot \mathrm{ha}^{-1}\right)$. perfilhos, assim para cada $50 \mathrm{~kg} \cdot \mathrm{ha}^{-1}$ de $\mathrm{N}$ aplicado, ocorreu incremento de $0,21 \%$ de material senescente na DTMS. O percentual de incremento de material morto na composição da matéria seca total, comparado ao tratamento testemunha com a maior dose de $\mathrm{N}$ foi de $27 \%$. É importante ressaltar que, quando se aumenta a dose de $\mathrm{N}$ aplicada, sem os devidos ajustes na utilização da forrageira, pode-se estar favorecendo a senescência e consequentemente o acúmulo de material morto na pastagem.

O acúmulo de lâmina foliar verde e de colmo determina a relação lâmina foliar:colmo, o que afetará o desempenho animal conforme a linearidade dessa inter-relação. A relação lâmina:colmo (RLC) do capim-xaraés nas águas decresceu $(\mathrm{P}<0,01)$ conforme aumentaram as doses de $\mathrm{N}$ aplicadas (Figura 12), apresentando comportamento quadrático negativo para o ponto de mínima RLC de 4,7 para a dose de 260,1 kg.ha ${ }^{-1}$ de N, 51\% menor em comparação à ausência de N, para a qual se registrou uma RLC de 7,2.

Deste modo, à medida que as doses de $\mathrm{N}$ foram incrementadas, a RLC apresentou queda progressiva, consequência direta do aumento do alongamento e da participação de colmo na altura e na DTMS da gramínea. Dessa forma, aumentos em altura do dossel quase sempre conduzem a uma redução concomitante na relação lâmina:colmo por perfilho, pelo fato de que, para suportar o peso de um órgão (no caso as folhas), o diâmetro das estruturas de suporte (colmos) altera-se em proporção direta à força requerida para suportá-lo e não isometricamente ao seu peso (Sbrissia, 2004).

Essa relação pode ser utilizada como um índice de valor nutritivo da forragem e, ao lado da altura do pasto e da disponibilidade de biomassa, condiciona a facilidade de apreensão da forragem pelo animal e, portanto, seu comportamento durante o pastejo (Alden \& Whitaker, 1970; Stobbs, 1973).

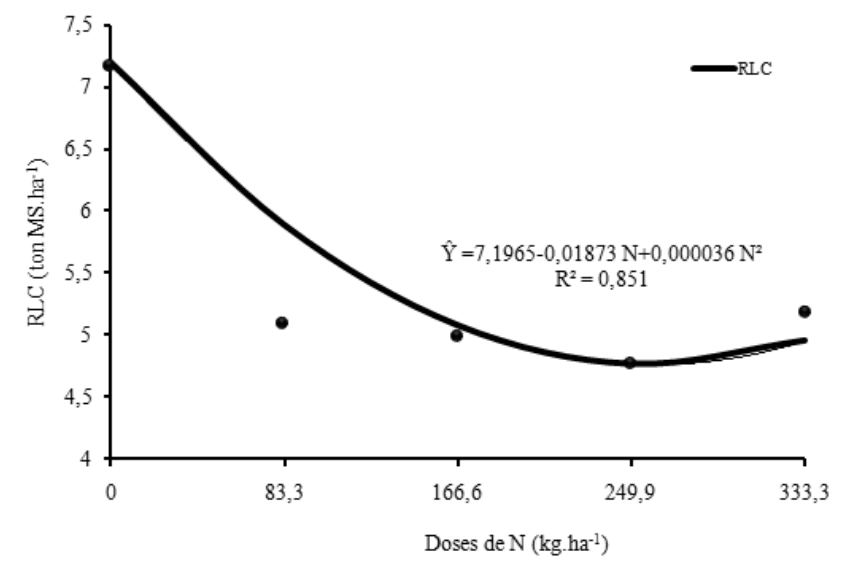

Figura 12 - Estimativa da relação lâmina:colmo do capim-xaraés durante o período das águas em função das doses de $\mathrm{N}\left(\mathrm{kg} \cdot \mathrm{ha}^{-1}\right)$. 
A análise de variância do IAF apresentou significância $(\mathrm{P}<0,10)$ à adubação nitrogenada (Figura 13). Após avaliação por meio de análise de regressão e polinômios ortogonais, verificou-se efeito quadrático das doses de $\mathrm{N}$ sobre o IAF.

Por meio da derivação da equação de regressão, observa-se que o ponto de máxima para o IAF nas águas seria alcançado mediante dose superior à dose máxima utilizada nesse estudo, quando a dose de $410 \mathrm{~kg} \cdot \mathrm{ha}^{-1}$ de $\mathrm{N}$ possibilitaria IAF de 7,7; 286\% maior comparada à ausência de N. No entanto, para a maior dose utilizada no estudo (333,3 kg.ha ${ }^{-1}$ de N), o IAF foi de 7,57. O aumento no IAF foi de $276 \%$ maior para a mais elevada dose de $\mathrm{N}$ em comparação ao tratamento testemunha (IAF $=2,01)$, sendo a eficiência de uso do $\mathrm{N}$ convertida em 0,83 unidades de IAF

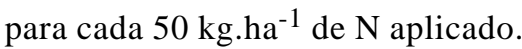

Ao analisar a relação entre o IAF e altura média do dossel no período das águas (Figura 14), observar que a maior altura nas águas foi de $63,95 \mathrm{~cm}$ para dose de $280,5 \mathrm{~kg} \mathrm{ha}^{-1}$ de N, o

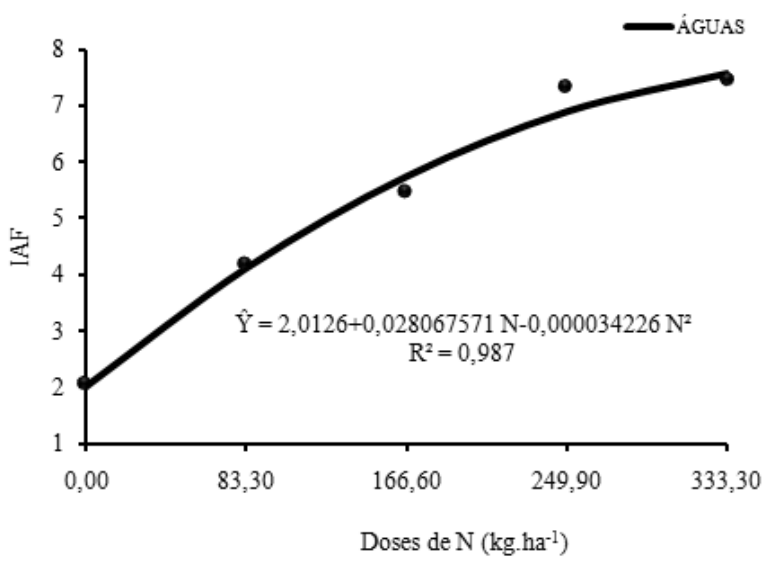

Figura 13 - Estimativa do IAF de capim-xaraés durante o período das águas em função das doses de $\mathrm{N}\left(\mathrm{kg} \cdot \mathrm{ha}^{-1}\right)$.

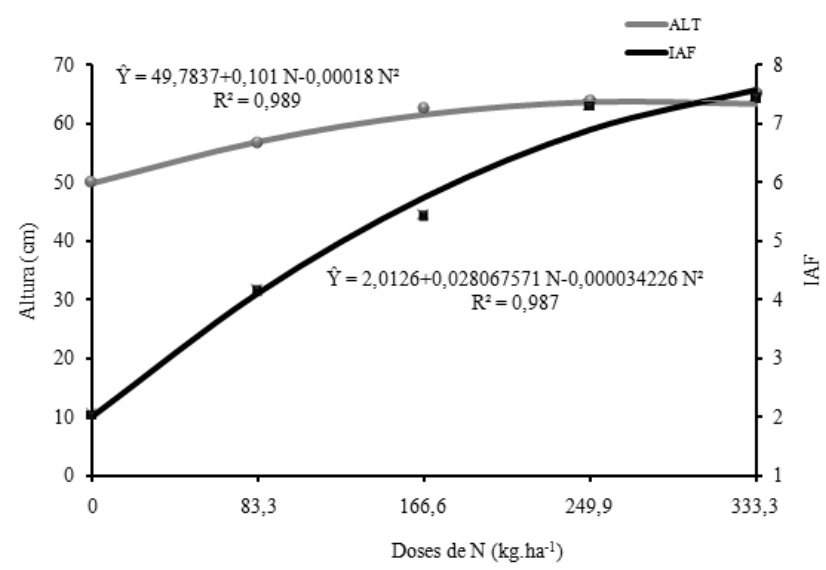

Figura 14 - Estimativa da relação do IAF e altura do capim-xaraés durante o período das águas em função das doses de $\mathrm{N}\left(\mathrm{kg} \cdot \mathrm{ha}^{-1}\right)$. que apresentou um IAF de 7,1 com disponibilidade total de matéria seca de 6 t.ha ${ }^{-1}$ de MS e disponibilidade de matéria seca de lâmina foliar igual a 3,98 t.ha-1 .

No entanto, quando se utilizou o IAF como parâmetro primário de decisão para o manejo, o maior IAF nas águas (IAF $=7,5$ ) foi obtido com a dose de 333,3 kg.ha- ${ }^{-1}$ de N, com altura média de $63,45 \mathrm{~cm}$ e disponibilidade total de matéria seca de 6,23 t.ha ${ }^{-1}$ de MS. Assim, para o período das águas, a adubação nitrogenada com a dose de 333,3 kg.ha ${ }^{-1}$ de N promoveu melhores índices produtivos de Brachiaria brizantha cv. Xaraés.

No entanto, quando se analisa a relação financeira com a produtividade, o melhor nível de adubação para as características agronômicas e estruturais do capim-xaraés para o período chuvoso foi de $280 \mathrm{~kg}$.ha ${ }^{-1}$ de N, devendo-se, porém, considerar os fatores edafoclimáticos da região onde será implantado e manejado o capim-xaraés.

\section{Conclusões}

A adubação nitrogenada contribui positivamente para o aumento do número de folhas totais do capim-xaraés, principalmente no período chuvoso, sendo recomendável a dose de $250 \mathrm{~kg}$ ha ${ }^{-1}$ de $\mathrm{N}$ nessa época do ano, quando se intensifica a disponibilidade de matéria seca de lâmina foliar verde. A densidade de perfilhos desta forrageira aumenta consideravelmente com o aumento das doses de nitrogênio aplicadas, permanecendo o efeito ao longo do ano, o qual garante a perenidade da gramínea no período chuvoso posterior, com rápido rebrota da forrageira. A adubação nitrogenada e a época do ano são componentes importantes que afetam a altura e o crescimento de Brachiaria brizantha cv. Xaraés, assim, quando se analisa o comportamento dos diferentes níveis de $\mathrm{N}$ ao longo do ano pode-se observar efeito mais acentuado dos tratamentos no período das águas, enquanto no período seco o efeito dos tratamentos se torna praticamente nulo.

\section{Referências}

ALEXANDRINO E.; NASCIMENTO JÚNIOR., D.; MOSQUIM, P.R. et al. Características morfogênicas e estruturais na rebrotação da Brachiaria brizantha cv. Marandu submetida a três doses de nitrogênio. Revista Brasileira de Zootecnia, v.33, n.6, p.1372-1379, 2004.

ALEXANDRINO, E.; GOMIDE, C.A.M.; CANDIDO, M.J.D. et al Período de descanso, características estruturais do dossel e ganho de peso vivo de novilhos em pastagem de capim-mombaça sob lotação intermitente. Revista Brasileira de Zootecnia, v.34, n.6, p.2174-2184, 2005.

ALMEIDA, E.X.; MARASCHIN, G.E.; HARTHMANN, O.E.L. et al. Oferta de forragem de capim-elefante anão "Mott" e a dinâmica da pastagem. Revista Brasileira de Zootecnia, v.29, n.5, p.1281-1287, 2000. 
CRUZ, P.; BOVAL, M. Effect of nitrogen on some morphogenetic traits of temperate and tropical perennial forage grasses. In: LEMAIRE, G.; HODGSON, J.; MORAES, A. et al. (Eds.) Grassland ecophysiology and grazing ecology. Wallingford: CABI Publishing, 2000. p.151-168.

EUCLIDES, V.P.B.; CARDOSO, E.G.; MACEDO, M.C.M. et al. Consumo voluntário de Brachiaria decumbens cv. Basilisk e Brachiaria brizantha cv. Marandu sob pastejo. Revista Brasileira de Zootecnia, v.29, n.6, p.2200-2208, 2000 (supl. 2).

FLORES, R.S.; EUCLIDES, V.P.B.; ABRÃO, M.P.C. et al. Desempenho animal, produção de forragem e características estruturais dos capins marandu e xaraés submetidos a intensidades de pastejo. Revista Brasileira de Zootecnia, v.37, n.8, p.1355-1365, 2008.

GARCEZ NETO, A.F.; NASCIMENTO JÙNIOR, D.; REGAZZI, A.J. et al. Respostas morfogênicas e estruturais de Panicum maximum cv. Mombaça sob diferentes níveis de adubação nitrogenada e alturas de corte. Revista Brasileira de Zootecnia, v.31, n.5, p.1890-1900, 2002.

GOMIDE, C.A.M. Características morfofisiológicas associadas ao manejo do capim-mombaça (Panicum maximum Jacq.). 2001. 107f. Tese (Doutorado em Zootecnia) - Universidade Federal de Viçosa, Viçosa, MG.

HODGSON, J. The control of herbage intake in the grazing ruminant. Proceedings of the Nutrition Society, v.44, p.339-346, 1985.

HODGSON, J. Grazing management: science into practice. London: Longman Scientific and Technical, 1990. 203p.

LEMAIRE, G.; CHAPMAN, D. Tissue flows in grazed plant communities. In: HODGSON, J.; ILLIUS, A.W. (Eds.) The ecology and management of grazing systems. London: CAB International, 1996. p.3-36.

MARTUSCELLO, J.A.; FONSECA, D.M.; NASCIMENTO JÚNIOR, D. et al. Características morfogênicas e estruturais do capimxaraés submetido à adubação nitrogenada e desfolhação. Revista Brasileira de Zootecnia, v.34, n.5, p.1475-1482, 2005.

MARTUSCELLO, J.A.; FONSECA, D.M.; NASCIMENTO JÚNIOR, D. et al. Características morfogênicas e estruturais de capimmassai submetido a adubação nitrogenada e desfolhação. Revista Brasileira de Zootecnia, v.35, n.3, p.665-671, 2006.

MARTUSCELLO, J.A.; JANK, J.; GONTIJO NETO, M.M. et al. Produção de gramíneas do gênero Brachiaria sob níveis de sombreamento. Revista Brasileira de Zootecnia, v.38, n.7, p.1183-1190, 2009.

MATTOS, J.L.S.; GOMIDE, J.A.; HUAMAN, C.A.M. Crescimento de espécies do gênero brachiaria, sob déficit hídrico, em casa de vegetação. Revista Brasileira de Zootecnia, v.34, n.3, p.746-754, 2005.

NABINGER, C. Princípios da exploração intensiva de pastagens. In: SIMPÓSIO SOBRE MANEJO DA PASTAGEM, 13., 1996, Piracicaba. Anais... Piracicaba: Fundação de Estudos Agrários Luiz de Queiroz, 1996. p.15-96.

PILBEAM, C.J. Effect of nitrogen supply on the growth and senescence of leaves of Lolium perenne with contrasting rates of leaf respiration. Annals of Botany, v.70, n.4, p.365-374, 1992.

RIBEIRO, A.C.; GUIMARÃES, P.T.G.; ALVARES, V.H. Recomendações para o uso de corretivos e fertilizantes em Minas Gerais. 5a Aproximação. Viçosa, MG: 1999. 359p.

SANTOS, P.M.; BALSALOBRE, M.A.A.; CORSI, M. Morphogenetic characteristics and management of Tanzania grass. Pesquisa Agropecuária Brasileira, v.38, n.8, p.991-997, 2003.

SBRISSIA, A.F.; DA SILVA, S.C.O ecossistema de pastagens e a produção animal. In: MATTOS, W.R.S. (Ed.) A produção animal na visão dos brasileiros. Piracicaba: SBZ, 2001. p.731-754.

SBRISSIA, A.F. Morfogênese, dinâmica do perfilhamento e do acúmulo de forragem em pastos de capim-Marandu sob lotação contínua. 171f. 2004. Tese (Doutorado em Agronomia - Ciência Animal e Pastagens) - Escola Superior de Agricultura Luiz de Queiroz, Piracicaba.

SILVA, M.M.P.; VASQUEZ, H.M.; BRESSAN-SMITH, R.E. et al. Respostas morfogênicas de gramíneas forrageiras tropicais sob diferentes condições hídricas do solo. Revista Brasileira de Zootecnia, v.34, n.5, p.1993-1504, 2005.

SOLLENBERGER, L.E.; BURNS, J.C. Canopy characteristics, ingestivo behavior and herbage intake in cultivated tropical grasslands. In: INTERNATIONAL GRASSLAND CONGRESS, 19., 2001, São Pedro. Proceedings... Piracicaba: FEALQ, 2001. p.321-327.

SOUSA, B.M.L.; NASCIMENTO JÚNIOR, D.; RODRIGUES, C.S. et al. Morphogenetic and structural characteristics of xaraes palisadegrass submitted to cutting heights. Revista Brasileira de Zootecnia, v.40, n.1, p.53-59, 2011. 